\title{
A relação homem-natureza e a práxis do turismo: um (re)encontro para a preservação
}

\author{
Bruna Raquel Alves Pinheiro, Artemísia dos Santos Soares, \\ Francisco Fransualdo de Azevedo
}

\begin{abstract}
RESUMO
O presente artigo constitui-se de um ensaio teórico conceitual focalizado nas relações homem-natureza que se dão no espaço. Acredita-se assim, que por meio da prática do turismo em ambientes naturais, o homem pode (re)encontrar-se consigo mesmo em uma relação individual, praxiológica que viabiliza a preservação ambiental. Para tanto, o estudo aborda posicionamentos de estudiosos do turismo, geografia e filosofia que versam acerca desta temática, embasados no imperativo da preservação, no conceito de totalidade, intrínseco a todos os elementos do Universo e na capacidade de percepção do turista. Portanto, defende-se a premissa de que o turismo pode ser um meio de sensibilização capaz de proporcionar a unicidade do ser humano com a natureza que na sociedade contemporânea ainda tem se revelado paradoxal.
\end{abstract}

PALAVRAS-CHAVE: Homem, Natureza, Preservação.

The man-nature relationship and praxis of tourism: a reunion for preservation

\section{ABSTRACT}

This is a theoretical-conceptual article focused on the relationships between mannature that occur in space. It is believed therefore that, throughout the practice of tourism in natural environments, man can reunite himself in a single and praxiologic relationship which makes possible environmental preservation. Thus, the study addresses attitudes of scholars of Tourism, Geography and Philosophy that converge on this theme. Such attitudes are based on the imperative of preservation, the intrinsic concept of totality to all elements of the Universe and the tourist's perception. Therefore, the premise that tourism can be a mean of awareness capable of providing the unity of mankind with nature is defended; though in contemporary society it has proved to be paradoxical.

KEYWORDS: Man, Nature, Preservation. 
A relação homem-natureza e a práxis do turismo: um (re)encontro para a preservação.

\section{Introdução}

O presente artigo propõe uma reflexão teórico-conceitual centrada nas relações homem-natureza que ocorrem no espaço no espaço geográfico, particularmente no que concerne ao ambiente natural da sociedade contemporânea. Nesse contexto, enfatiza-se a atividade turística como instrumento de sensibilização para a preservação de paisagens naturais, configurando-se como uma práxis do turismo. Com este objetivo, utiliza-se a abordagem dialética acerca do uso dos espaços naturais objetivando sua preservação por meio de posicionamentos de estudiosos que tratam da temática em um pensamento que na atual sociedade ainda se mostra paradoxal.

Neste sentido, os autores deste estudo levantam a hipótese de que a natureza pode influenciar a capacidade de consumo em geral, mas em particular da classe mais abastada da sociedade no que se refere ao uso dos atrativos naturais para fins de lazer e entretenimento. Diante disso, é possível que haja sensibilização por intermédio do contato pessoal com o meio ambiente no sentido de preservá-lo, levando-se em conta a admissão do conceito de totalidade inerente a todos os elementos do Universo. Desta feita, ao preservar o meio ambiente, consequentemente, preserva-se a si mesmo. Portanto, a natureza, como será abordada aqui, é analisada como algo que transmite sensações diferentes e únicas em cada turista, em uma relação pessoal, praxiológica e considerada até mesmo semi-espiritual.

O ser humano está em intensa construção de seus valores, conhecimento e amadurecimento, ou seja, de sua identidade. Sendo assim, a viagem é um dos meios que possibilita ao sujeito buscar o seu "ser" interior fora da sua experiência cotidiana, isto é, fora do seu espaço vivido. Assim, o então turista move-se com a nítida imagem do prazer, que the fornece a imaginação de um ideário de desprendimento das diferenças, de superioridade ou inferioridade social, de possibilidades de trocas, enfim de um rápido e progressivo enraizamento e desenraizamento sociogeográfico dos destinos (DE BOTTON, 2003; KRIPPENDORF, 2003).

Existe a premissa de que o relacionamento do turista com a natureza seja contraditório em função do individualismo do ser humano. Tal pensamento pode ser exemplificado na visão que normalmente se tem da atividade turística como promotora de danos ambientais, fundamentado no crescimento da infraestutura turística que impactam o espaço no qual a atividade se realiza.

A relação do turismo com o meio ambiente é complexa, pois numerosos acontecimentos de conflito são registrados resultantes de medidas tomadas em função da atividade turística que provocam efeitos perversos e difíceis de controlar e/ou reparar. Com efeito, o desafio encontra-se no equilíbrio entre o desenvolvimento da atividade e a proteção ambiental.

Face ao exposto, os autores tencionam destacar o destino turístico que possui o meio ambiente natural como principal atrativo de visitação como detentor de uma função que vai além da visão reducionista e paisagística, sobretudo acreditando que o valor da paisagem não será determinado unicamente por critérios formais estéticos (como a harmonia das cores ou a disposição das linhas), nem por questões exclusivamente economicistas, mas colocando em evidência o potencial que os lugares possuem em despertar a mente para o sublime, possibilitando a reflexão e o entendimento do ser humano sobre si 
mesmo e seu papel dentro da totalidade da natureza.

\section{Turismo e Meio Ambiente: um imperativo da preservação?}

Sabe-se que qualquer atividade econômica em si, impacta sobre o meio ambiente, logo com a atividade turística não poderia ser diferente. De acordo com Mendonça (1996, p. 19), "onde há turismo há degradação ambiental". A autora afirma que a atividade turística ocorre essencialmente por meio da apropriação e exploração da natureza e dos residentes que ao fincar moradia já degradavam o ambiente de uma forma particular. Cabe em cada caso avaliar os diferentes níveis de degradação proporcionado, ora pelos residentes, ora pelos não-residentes. Nota-se que ocorre de fato uma intensificação do processo de degradação com a turistificação, haja vista a sobrecarga de uso dos recursos existentes, bem como a maior geração de resíduos sólidos, edificações, etc.

Sendo assim, o turismo se coloca como uma indústria caracterizada por relações muitas vezes superficiais com o lugar. Turner e Ash apud Pearce (2003), também acreditam que o turismo mantém contato superficial com a natureza, tendo-se em vista que o sistema turístico resguarda o turista de um contato mais profundo, através dos pacotes de viagem oferecidos pelas operadoras que definem quando e o que visitar, bem como o comportamento do turista.

Tal racionalidade imposta pela indústria sufoca e aproxima o turista de "pseudoconhecimentos" fragmentados, que não induzem à sensibilização, o que pode ocasionar relações predatórias entre o homem e a natureza, devido a falta de respeito resultante do superficial conhecimento dos visitantes (CARLOS, 1996; MENDONÇA, 1996).

No intuito de assegurar a preservação ambiental para as gerações futuras, o homem cria leis objetivando a normatização do uso da natureza. Em razão disso, uma das medidas tomadas com a finalidade de proteger o conjunto de ecossistemas do Brasil e impedir a deterioração ambiental foi a implementação de um sistema de Áreas Naturais Protegidas, que tenciona garantir a manutenção da diversidade biológica (DIAS, 2007).

Nessa perspectiva, a beleza cênica natural em conjunto com os elementos culturais existentes nas áreas naturais legalmente protegidas, representam pólos de atração para os visitantes de todo o mundo, inclusive os habitantes da região receptora (LIMA, 2003).

Boo apud LIMA (2003) confirma esta tendência ao informar que os turistas estão visitando cada vez mais parques e reservas ao redor do mundo, como anteriormente não ocorria, em busca de experiências que os façam valorizar e compreender o ambiente natural em que vivem.

Com esta preocupação, Mendonça (1996) atenta para a experiência do turista, pois como ela mesma afirma, é através da vivência mais próxima com a natureza, que o visitante será capaz de respeitar o espaço. Sendo possível, assim, a relação homem e natureza com a apreensão da realidade na qual se acham inseridos favorecendo a preservação ambiental.

Contudo, a atividade turística faz parte da economia de um mundo globalizado, que retrata o meio ambiente como atrativo mercadológico da natureza (AZEVEDO, 2003). É neste entendimento que Rodrigues (1996b) aufere ao turismo a responsabilidade por 
A relação homem-natureza e a práxis do turismo: um (re)encontro para a preservação.

destruir aquilo que lhe originou. A autora assinala a exploração $X$ conservação e esclarece que a natureza não é em si própria responsável única pela venda de um destino, mas sim a forma como se dá a exploração do espaço pelo homem é que caracteriza a mercantilização da natureza, ou seja, o uso do espaço pelo turismo.

Bedim (2007), seguindo este pensamento, afirma que no mundo globalizado, o espaço natural destinado ao turismo é um espaço-mercadoria, cuja essência está envolta em simulacros, onde o local é produzido e reproduzido enquanto mercadoria reprodutível. Neste processo de apropriação do meio natural pelo homem, o autor afirma que o sujeito antropomorfiza a sua natureza externa e, consequentemente, transforma a sua própria natureza interior. Bedim (idem) ressalta ainda, que o ambiente sem a intervenção do homem, à luz da teleologia ${ }^{1}$, possui papel de objeto e meio de trabalho para o homem. Focando assim a satisfação das necessidades humanas, processo em que são originadas as riquezas.

Esta realidade mercantilista se contrapõe à ideia de revalorização da natureza pelo homem, figurando-se como necessidade premente do homem no estágio atual de desenvolvimento da sociedade urbano-industrial. Neste novo pensamento, a natureza aparece como algo exótico, apaziguador e belo, ao contrário do que ocorreu em outros períodos da história, quando a natureza era vista como sinônimo de perigo, do incerto ou até mesmo como ameaça, basta observar a teoria do miasma².

Este entendimento sobre (re)valorização da natureza está no cerne da atual crise ecológica, refletindo de algum modo nos espaços de uso turístico. Segundo Beni (2004, p. 52), "isto talvez possa ser traduzido como reflexo do conflito existente entre os aspectos culturais e naturais do espaço", sabendo-se que a atividade turística consome elementarmente espaço que, por vezes, é manipulado de forma irracional (CRUZ, 2002).

Isso ocorre porque "o conceito de natureza tem sido redefinido e multiplicado pelos diferentes usuários, ganhando uma extensa pluralidade" (MARINHO, 1999, apud BRUHNS, 2009, p. 21). A aproximação do sentido das palavras "natureza", "paisagem" e "cenário" demonstra as transformações acerca da visão de mundo, passando a natureza a significar não mais a totalidade, o physis do grego pré-socrático, mas a aproximação do homem ao campo, ao selvagem (TUAN, 1980 apud BRUHNS, 2009). Assim, nessa ideia de "confronto homem-natureza" mostra-se imbutida a percepção da natureza separada do homem.

Tal entendimento pode ser constatado, a partir da capacidade que as sociedades pós-industriais possuem em produzir novas necessidades, que sofisticam cada vez mais a relação homem/homem e homem/natureza (BEDIM, 2007). Nesse contexto, "o homem contemporâneo vive profundas dicotomias. Dificilmente se considera elemento da natureza, mas sim apartado dela, como observador e/ou explorador". (REIGOTA, 1995, apud BRUHNS, 2009, p. 23).

Por isso, a problemática da relação entre turismo e natureza, sobretudo em áreas legalmente protegidas, tem desafiado os planejadores e pesquisadores da atividade. Atualmente os modelos estratégicos para o planejamento turístico estão cada vez mais evidenciando a necessária integração de todos os agentes que compõem o destino turístico: turistas, residentes, setores privados e públicos (DIAS, 2007).

Diante da problemática apresentada percebe-se que, experienciar o contato com a natureza, tornou-se o imperativo determinado pelo modo de vida das populações urbanas 
da contemporaneidade, numa tentativa de resgatar um elo ancestral por vezes considerado obsoleto pelo ser humano, mas presente em sua essência. (SONAGLIO, 2006). Nas cidades, às vezes se tem a sensação de que a natureza encontra-se distante do homem, mas concretamente ela está absolutamente presente e abrange o próprio homem em sua relação com o universo, através do ar, da água, da luz, etc. Tudo isso absolutamente indispensável para a permanência deste no planeta.

Mostra-se, pois, premente a necessidade de se ter outra uma concepção, através, por exemplo, de uma integração transformadora entre os sistemas de objetos e os sistemas de ações, sendo estes, fatores de influência sobre os objetos. Portanto, o turismo, surge nesse contexto como possível instrumento de (re)integração das relações entre o homem e a natureza, (re)estabelecendo no consciente do homem a totalidade inerente à sua essência.

\section{A natureza e o homem na práxis do turismo}

Primeiramente, vale pontuar o significado de teoria, prática e práxis. Em suma, teoria é um conjunto de princípios fundamentais duma arte ou duma ciência, prática é a aplicação da teoria e na práxis é quando a atividade exercida pelo homem é auxiliada pelo conhecimento intectual visando a transformação de uma realidade (FERREIRA, 2001; PEREIRA, 1988).

Pereira (1988), afirma que em todos os aspectos que analisarmos a relação teoria, prática e práxis é o homem quem deve estar na centralidade da análise. "O homem, com sua ação, sua presença e sua relação com o mundo. Uma presença e uma ação que é ação sobre o mundo material e, consequentemente sobre si mesmo" (p. 69).

Ao abordar a conceituação metodológica da teoria, o autor enfatiza a racionalidade humana como agente de transformação do meio e, por conseguinte de si próprio. Seguindo esta lógica, a abstração que não se concretiza em ação não ascendeu à práxis, pois cabe ao homem a capacidade de distanciamento da natureza para sobre ela refletir, e a partir dela também ser transformado gerando através deste processo o que Pereira (1988) denomina como práxis. Assim, a ação praxiológica do homem "transforma a natureza e, ao transformá-la, transforma a si mesmo. Em maior ou menor medida é a práxis" (p. 72).

Desta feita, exemplifica-se através da teoria "The Optimal Arousol" de Iso-Ahola, a práxis na atividade turística, ou seja, a teoria em questão afirma que as pessoas viajam para retornarem aos seus locais de morada melhor do que eram, na ideia de que as viagens, através de suas atividades de lazer, reconstroem e recriam o homem, para curar e sustentar o corpo e a alma, proporcionando uma fonte de forças essenciais que trazem um sentido à vida (KRIPPENDORF, 2003).

Nesta transformação através do turismo, as paisagens naturais inseridas (ou não) em espaços legalmente protegidos podem ser um instrumento desta mudança. De acordo com o filósofo De Botton (2003), a proximidade de uma catarata, de uma montanha ou de qualquer outro elemento da natureza, torna mais difícil a vivência de inimizades e desejos adjetos. Em sua análise pelos escritos de Wordsworth ${ }^{4}$, ele observou que a natureza promove uma motivação para a busca dos objetivos individuais e coletivos, pensando o de- 
A relação homem-natureza e a práxis do turismo: um (re)encontro para a preservação.

sejável e bom, formando-se assim uma "imagem da razão correta" que forneceria o equilíbrio dos impulsos desvirtuados da vida urbana.

A filosofia preconiza que o conceito da capacidade de percepção, modifica a situação. Como pode acontecer na prática de ecoturismo, embora a trilha ainda possa ser fisicamente percorrida, ela já não significa aquele ermo ainda não desbravado que o visitante esperava contemplar. Pois, sugere-se que a percepção seja superior às sensações meramente físicas, portanto, nem sempre se percebe aquilo que se imaginava, que iria ser vivenciado antes da viagem.

A capacidade de percepção é volátil, pois depende de determinadas concepções da natureza e das circunstâncias pelas quais os visitantes desejam contemplá-la. Walter apud Urry (1996) demonstra esta reflexão com o exemplo de uma montanha nos Alpes, mostrando que, como sendo um bem material, ela pode ser contemplada pela sua grandiosidade e beleza, em conformidade com uma paisagem alpina idealizada. Essa mesma montanha, todavia, pode ser encarada como um bem posicional, uma espécie de santuário da natureza que os indivíduos desejam gozar na solidão. Surge assim, aquilo que Urry (1996) denominou de "olhar romântico" do turista, na qual a ênfase é colocada na solidão, na privacidade e em um relacionamento pessoal e semi-espiritual com o objeto do olhar.

A conotação de divindade e sacralidade dada a certos locais de beleza natural está associada ao legado da cultura judaico-cristã. Isto explica, em parte, a defesa de alguns ambientalistas em proibirem a visitação pública às Unidades de Conservação, considerando o turismo como uma ameaça à vida selvagem e como mecanismo indutor de ações depredatórias (SCHAMA apud BEDIM, 2007).

Em razão disso, o planejamento e a gestão do turismo em espaços legalmente protegidos precisam estar direcionados por um novo pensar que (re)constitua a relação integrada e integradora entre as várias partes que compõem a totalidade da natureza. A prática do ecoturismo tem essa incumbência de desvendar o "sagrado"5 que está intrínseco em todos os que procuram o "religare" com a natureza (SONAGLIO, 2006).

Para De Botton (2003), as pessoas possuem uma identidade maleável, pois mudam de acordo com quem - e às vezes com o que - estamos. A companhia de certas pessoas estimula a experiência turística, de forma que as reações em relação ao que é visitado são crucialmente moldadas pela sua visão pessoal de quem o outro pode vir a ser. Entretanto, quando um indivíduo está na presença de uma catarata ou montanha (entes que no fundo não tem interesses conscientes, portanto não poderiam encorajar ou censurar comportamentos) estas podem, segundo Wordsworth apud De Botton (2003), exercer certa influência quando os elementos naturais têm o poder de sugerir valores, como por exemplo, o carvalho, a dignidade; pinheiros, a determinação; lagos, a calma; as flores, humildade e mansidão.

De acordo com o poeta inglês, a beleza da natureza pode estimular a localizar o bem nas pessoas. Duas pessoas paradas numa saliência rochosa com vista para um regato e um majestoso vale coberto de bosques poderiam mudar não só sua relação com a natureza, mas sua relação entre elas.

De Botton (2003) relata em seu livro "A arte de viajar", sua excursão pelo deserto do Sinai. Então, diante da imensidão de rochas, camadas de granito, tabuleiros de cascaIho torrando ao sol e montanhas de lava solidificada ele interroga-se acerca da procura do 
ser humano por aquele tipo de sensação de pequenez que a visão da grandeza da natureza diante de si o faz(ia) sentir. O filósofo repara que o ser humano que normalmente sente-se humilhado diante das relações de poder (geralmente mesquinhas) existentes na sociedade, faz referência ao que tem poder e mostra-se nobre perante a grandeza da natureza.

Este tipo de lugar-natureza tão sublime permite ao turista encarar uma deficiência conhecida de outra forma, pois eles repetem uma lição que a vida rotineira costuma ensinar com crueldade, a de que o universo é mais poderoso que o ser humano, sendo este, frágil e efêmero. Portanto, visitar estes lugares tão majestosos não refletirá humilhação, ao contrário, promoverá inspiração aos visitantes que se sentirão privilegiados diante de exigências tão grandiosas. A noção de assombro pode até se transformar em um desejo de culto.

\section{Conclusão}

Diante do exposto, depreende-se que na relação homem-natureza, na perspectiva de um turismo sensível à natureza almeja-se (ou ao menos se deveria almejar) um mundo em real totalidade, onde se possa (re)encontrar um estado de equilíbrio, consciência sobre a unicidade que permeia o universo, em conformidade com a natureza e atuando solidariamente para com as gerações futuras. Para isso, há a necessidade da educação para a conscientização, isto é, "o processo que busca conscientizar o turista e aqueles que mantêm contato com o mesmo, para o entendimento de que o homem é a própria natureza.

O turismo nos espaços naturais, levando em consideração a questão praxiológica demonstra ser uma saída possível para o uso de áreas naturais protegidas pela atividade turística, objetivando a sua preservação. Pois, a atividade, quando vista e planejada como um evento, fato, ou conjunto de relações que envolve infinitas facetas do existir humano, valoriza o atrativo natural e sai da superficialidade comercial para um espaço qualitativo de reflexão, de reencontro entre o homem e o meio ambiente.

Tudo isso por intermédio da prática de um turismo não somente de apreciação da paisagem, mas que vai além, através dos fatos e relatos que foram expressos neste estudo, entre os visitantes de lugares "sublimes" que revigoram pela sua grandiosidade. Entendese, portanto, que desta forma o turista certamente poderá tirar melhor proveito das viagens, assim como também a natureza, por conseguinte, a humanidade.

Acredita-se que os impactos ambientais podem ser reduzidos quando há a relação com o meio de um olhar romântico do turista, pois isso pode aproximá-lo ainda mais dos elementos da natureza, de forma distinta, e distante do consumismo da sociedade pósmoderna, pois a importância com a transformação por meio de uma prática, ou seja, o turismo, podem subverter a ordem econômica de ter para ser. Atitudes desse gênero podem tornar a conscientização ambiental uma realização espontânea e fluida.

Desenvolve-se, portanto, uma nova sensibilidade em uma parcela da população turística que pratica turismo em ambientes naturais, não tolerando abusos cometidos contra a natureza, pois estes acabariam também "abusando" os seus visitantes os quais neces- 
A relação homem-natureza e a práxis do turismo: um (re)encontro para a preservação.

sitam destas paisagens para se reencontrarem enquanto seres também pertencentes ao meio natural.

Cabe, pois, concluir que a atividade turística na natureza pode ter como finalidade despertar a mente do homem/turista para o sublime, possibilitando a reflexão e o entendimento do ser humano sobre si mesmo e seu papel dentro da totalidade da natureza. Tal conhecimento pode contribuir, de alguma maneira, para a preservação ambiental, em uma contemporaneidade permeada de relações efêmeras e fugazes, que em alguns casos evidenciam o olhar de insignificância com o qual é vista a natureza.

Assim, contrariando a realidade atual que valoriza o usufruto inconsequente de tudo que cerca o homem em benefício do individual, o turismo, nas palavras de $\mathrm{Pa}$ nosso Netto (2005) é a busca da experiência humana, da construção do "ser" interno do homem, fazendo-o se aperceber como integrante da totalidade da natureza. Isso demonstra que devido a realidade apresentada observa-se que, por vezes, torna-se necessário um (re)encontro que possibilite a descoberta daquilo que sempre coexistiu com o homem no espaço, contrariando o que Santos (2006) afirma: não é a natureza que é cega e sim o homem.

\section{Referências bibliográficas}

AZEVEDO, J. "Enraização" de propostas turísticas. In: RODRIGUES, A. Turismo e desenvolvimento local. 3. ed. São Paulo: Hucitec, 2002.

BEDIM, B.P. O espaço capitalista da natureza e seu (contra) uso turístico: a dialética da visitação pública em áreas protegidas - um ensaio teórico. Caderno Virtual de Turismo. Rio de Janeiro, v. 7, n. 3, pp. 76-89, 2007.

BENI, M.C. Análise estrutural do turismo. São Paulo: Editora Senac, 2004.

CARLOS, A.F.A. O turismo e a produção do não - lugar. In: YÁZIGI, E.; CARLOS, A.F.A.; CRUZ, R.C.A. (org), Turismo: espaço, paisagem e cultura. São Paulo: Editora Hucitec, 1996. pgs 25-37.

BRUHNS, H.T. A busca pela natureza: turismo e aventura. Barueri, SP:Manole: 2009.

CRUZ, R.C. Política de turismo e território. 3. ed. São Paulo: Contexto, 2002.

DE BOTTON, A. A arte de viajar. Rio de Janeiro: Rocco, 2003.

DIAS, R. Turismo sustentável e meio ambiente. São Paulo: Atlas, 2007.

FERREIRA, A.B.H. Miniaurélio século XXI Escolar: o minidicionário da língua portuguesa. 4 ed. Rio de Janeiro: Nova Fronteira, 2001.

GIDDENS, A. Novas regras do método sociológico: uma crítica positiva dos sociólogos. Rio de Janeiro: Zahar, 1978. 
HALL, C.M. Planejamento turístico: políticas, processos e relacionamentos. São Paulo: Contexto, 2001.

KRIPPENDORF, J. Sociologia do turismo. 3. ed. São Paulo: Aleph, 2003.

LIMA, M. L. C. (Eco) turismo em Unidades de Conservação. In: RODRIGUES, A. B.; Ecoturismo no Brasil: possibilidades e limites. São Paulo: Contexto, 2003.

MENDONÇA, R. Turismo e meio ambiente: uma falsa oposição? In: LEMOS, A. I. G. (org), Turismo: impactos socioambientais. São Paulo: Editora Hucitec, 1996.

NICOLESCU, B. O manifesto da transdisciplinaridade. São Paulo: TRIOM, 1999.

PANOSSO NETTO, A. Filosofia do turismo: teoria e epistemologia. São Paulo: Editora Aleph, 2005.

PEREIRA, O. O que é teoria. 6. ed. São Paulo: Brasiliense, 1988.

PEARCE, D.G. Geografia do turismo: fluxos e regiões no mercado e viagens. São Paulo: Aleph, 2003.

RODRIGUES, A. B. Desafios para os estudiosos do turismo. In: RODRIGUES, A. B. (org), Turismo e geografia: reflexões teóricas e enfoques regionais. São Paulo: Editora Hucitec, 1996a.

RODRIGUES. A. M. A produção e o consumo do espaço para o turismo e a problemática ambiental. In: YÁZIGI, E.; CARLOS, A.F.A.; CRUZ, R.C.A. (org), Turismo: espaço, paisagem e cultura. São Paulo: Editora Hucitec, 1996b.

SANTOS, M. A natureza do espaço: técnica e tempo, razão e emoção. 4. ed. São Paulo: Editora da Universidade de São Paulo, 2006.

SONAGLIO, K.E. A transdisciplinaridade no processo de planejamento e gestão do ecoturismo em unidades de conservação. 2006. Tese (Doutorado em Engenharia Ambiental) Universidade Federal de Santa Catarina, Florianópolis.

URRY, J. O olhar do turista - Lazer e viagens nas sociedades contemporâneas. São Paulo: Studio Nobel, 1996.

VELLOSO, M.P. Os restos na história: percepções sobre estudos. Ciênc. Saúde coletiva. Rio de Janeiro. V.13, n.6, Dez.2008. Disponível em: <http://www.scielosp.org/ scielo.php?script=sciarttext\&pid=\$14138123200800600031\&Ing=en\&nrm=iso> Acesso em: 22 mai 2009. 
A relação homem-natureza e a práxis do turismo: um (re)encontro para a preservação.

\section{NOTAS:}

${ }^{1}$ Neste caso a Teleologia diz respeito à qualidade do homem em possuir consciência, ao contrário da irracionalidade dos outros animais.

${ }^{2}$ Acreditava-se na Idade Média que as enfermidades poderiam ser transmitidas a partir de qualquer contato com o ar proveniente do meio ambiente (VELLOSO, 2008).

${ }^{3}$ Os objetos são tudo o que existe na superfície da Terra, toda herança da história natural e todo resultado da ação humana (SANTOS, 2006).

${ }^{4}$ William Wordsworth (1770- 1850) foi um poeta romântico inglês que ficou conhecido por seus poemas de enaltecimento da natureza de sua terra natal, o Distrito dos Lagos. Sua obra influenciou o turismo na região ao ponto de transformar a base da economia local de agricultura para turismo.

${ }^{5}$ Sagrado, segundo Nicolescu (1999), é aquilo que não se submete a nenhuma racionalização. O sagrado não implica necessariamente na crença em Deus em deuses ou espíritos. O sagrado, antes de qualquer coisa, é uma experiência que se traduz por um sentimento. Religare, segundo o mesmo autor, traduz o sentido de religar, aquilo que liga (espaço do sagrado).

Bruna Raquel Alves Pinheiro: Universidade Federal do Rio Grande do Norte.

Email:brunaraquele@gmail.com

Link para o currículo Lattes: http://lattes.cnpq.br/8775029359416792

Artemísia dos Santos Soares : Universidade Federal do Rio Grande do Norte.

Email:artemisiasoares@yahoo.com.br

Link para o currículo Lattes: http://lattes.cnpq.br/1052024626478722

Francisco Fransualdo de Azevedo: Universidade Federal do Rio Grande do Norte.

Email:ffazevedo@gmail.com

Link para o currículo Lattes: http://lattes.cnpq.br/2719998085102847

Data de submissão: 29 de setembro de 2009.

Data do aceite: 08 de maio de 2010. 